\title{
ECO-FRIENDLY ENZYMATIC SYNTHESIS OF ANISYL PROPIONATE MEDIATED BY LIPASE B FROM CANDIDA ANTARCTICA
}

\author{
DIANA MARIA SCROB, MIHAI ANDREI LĂCĂTUȘa, \\ ADRIAN IOAN DUDU ${ }^{a *}$
}

\begin{abstract}
In this paper we report a biocatalytic approach for the efficient synthesis of anisyl propionate by direct esterification of anisyl alcohol with propionic acid mediated by commercially available Novozym 435, in presence of molecular sieves which serves for the efficient removal of water formed in the reaction. Process optimization was performed regarding the optimal solvent (2-methyltetrahydrofuran), temperature $\left(60^{\circ} \mathrm{C}\right)$, and molecular sieves load $(100 \mathrm{mg} / \mathrm{mL})$. Further scaling-ups were performed under optimal conditions increasing the substrates concentration up to $1000 \mathrm{mM}$ with unaltered conversions in anisyl propionate (>95\% after 6 hours reaction time).
\end{abstract}

Keywords: lipase, aroma, flavor, biocatalysis, esterification, green solvent

\section{INTRODUCTION}

In recent years the demand for natural products is increasing, therefore the development of biotechnological processes for the production of flavor compounds has been encouraged. Flavor is usually the result of the presence, within complex matrices, of various volatile and nonvolatile components which possess diverse chemical and organoleptic properties. The nonvolatile compounds contribute mainly to the taste, while the volatile ones influence both the taste and aroma [1].

Aroma esters are obtained nowadays by two methods: extraction from natural sources, or by chemical synthesis. Both methods have some disadvantages, for example the extraction from natural sources demands large amounts of starting material to obtain aroma compounds with relatively

\footnotetext{
a Enzymology and Applied Biocatalysis Research Center, Faculty of Chemistry and Chemical Engineering, Babeș-Bolyai University, Arany János str. 11, RO-400028, Cluj-Napoca, Romania *Corresponding author: adrian.dudu@ubbcluj.ro
} 
low yields and purity. The chemical synthesis of aroma compounds demands the use of toxic reagents and the obtained products, most of the time, demand further purification. These inconveniences can be overcomed by employing a green, biocatalytic approach for aroma esters synthesis, as previously reported [2], [3].

Many enzymatic processes for the preparation of aroma esters were recently developed. For example, the synthesis of banana flavor compounds by esterification reactions mediated by lipase from Thermomyces lanuginosus was already reported [4]. Short-chain flavor esters were obtained from natural sources in presence of tailored magnetic biocatalysts containing lipase $B$ from Candida antarctica (CaL-B) [5]. Moreover, the Novozym 435 (CaL-B adsorbed on Lewatit VP OC 1600) mediated preparation of benzyl butyrate by the esterification of benzyl alcohol with butyric acid in a solvent-free system (SFS) was also described [6]. Lipase from Burkholderia ambifaria immobilized on a mesoporous $\mathrm{TiO}_{2}$ based support functionalized with phenylaminopropyl trimethoxysilane was used for the synthesis of cinnamyl acetate [7]. Ethyl butyrate and isoamyl acetate, flavor esters found in pineapple and bananas, were prepared in presence of Candida rugosa lipase ( $\mathrm{CrL}$ ) covalently immobilized on multiwalled carbon nanotubes (MWCNTs) [8]. Anisyl propionate is a flavor ester used as a flavor or fragrance agent in the food industry or as a perfuming agent in the cosmetics.

Due to its versatility and wide application range, the commercially available immobilized lipase B from Candida antarctica was chosen for this study, as it was applied with great success for the enantiospecific production of atenolol acetate [9], in the production of flavor esters [10], [11], and in the enzymatic kinetic resolution of racemic secondary alcohols [12], [13].

2-Methyl-tetrahydrofuran (2-MeTHF), a green solvent derived from renewable resources (from furfural or levulinic acid, for example), is considered a promising alternative solvent in the search for environmentally friendly synthesis strategies. This solvent is characterized by its low miscibility with water, low boiling point and higher stability against peroxide formation, when compared with other cyclic-ethers (tetrahydrofuran, for example). Preliminary toxicological assessments support the use of 2-MeTHF in the pharmaceutical industry [14]. 2-MeTHF has also been successfully used as green solvent in our previous study for biodiesel additives preparation [15].

Based on the above, the main objective of the present work was to prepare anisyl propionate in a reaction system formed of anisyl alcohol, propionic acid, 2-MeTHF as a green and efficient solvent, Novozym 435 as biocatalyst and molecular sieves as an efficient tool to remove the water formed in the system, therefore shifting the reaction equilibrium towards ester formation. 


\section{RESULTS AND DISCUSSION}

In our first approach the reaction conditions were optimized performing analytical scale biotransformations. The obtained results served as a prerequisite for further experiments in order to maximize the productivity of the procedure.

To shift the equilibrium of the esterification reaction for total conversion of anisyl alcohol into the desired anisyl propionate, the mandatory water removal has been achieved with molecular sieves, as shown in Scheme 1.

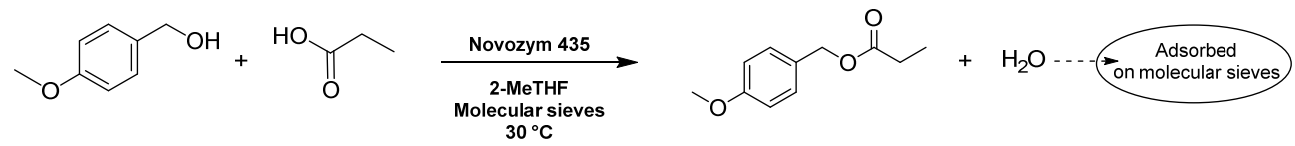

Scheme 1. Synthesis of anisyl propanoate by direct esterification of para-methoxybenzyl alcohol with propionic acid mediated by Novozym 435 in 2-MeTHF in presence of molecular sieves.

\section{Solvent screening}

The esterification reaction of anisyl alcohol with propionic acid mediated by Novozym 435 was tested in five solvents with different polarity.

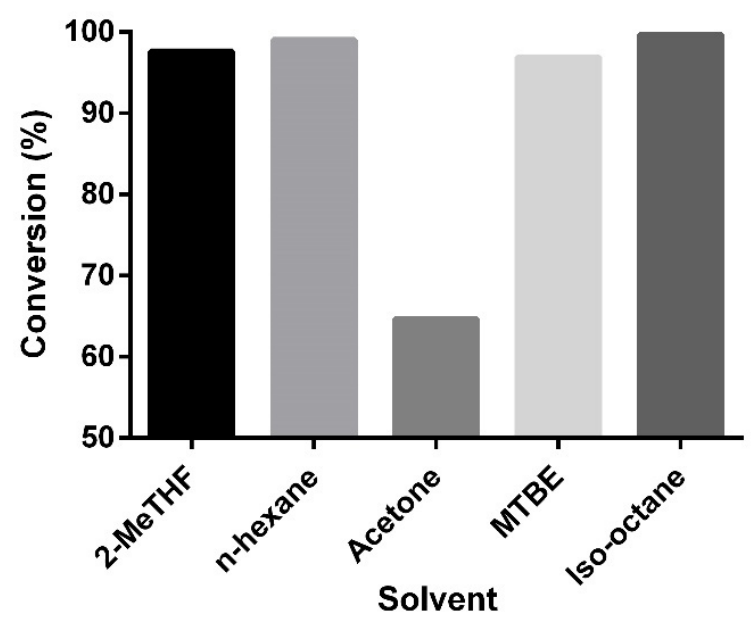

Figure 1. Solvent screening. Reaction conditions: $10 \mathrm{mM}$ anisyl alcohol, 2 equiv. propionic acid, $25 \mathrm{mg}$ Novozym 435, $1 \mathrm{~mL}$ solvent, $50 \mathrm{mg}$ molecular sieves, $800 \mathrm{rpm}, 30^{\circ} \mathrm{C}, 12 \mathrm{~h}$.

As it can be seen in Figure 1 high enzymatic activity was found in $n$-hexane, iso-octane (over $98 \%$, in both solvents) and in ethers (MTBE and 2-MeTHF, $\sim 96 \%)$, while much lower conversion ( 65\%) was obtained in 
acetone. Since excellent results were obtained also in 2-MeTHF, further experiments were performed in this solvent, also taking into account its classification as a green solvent.

\section{Substrate concentration screening}

In order to increase the productivity of the enzymatic esterification, the influence of the substrate (anisyl alcohol) concentration (10-50 mM) upon the reaction conversion was studied, at constant alcohol: propionic acid molar ratio (1:2), biocatalyst $(25 \mathrm{mg} / \mathrm{mL})$ and molecular sieves load $(50 \mathrm{mg} / \mathrm{mL})$.

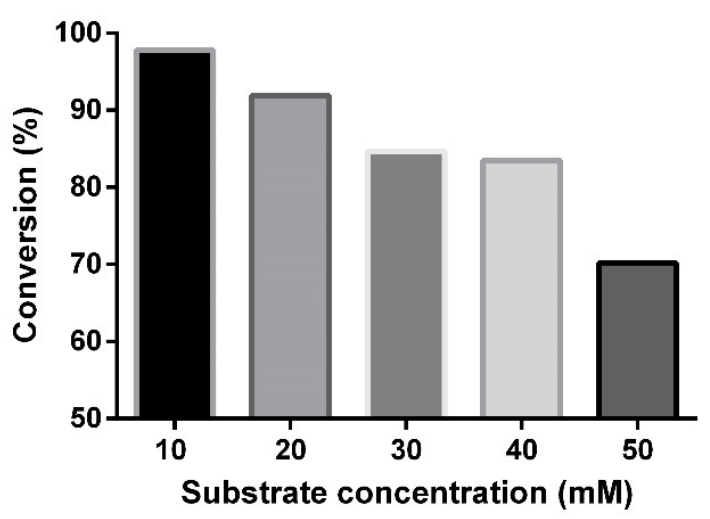

Figure 2. Influence of the anisyl alcohol concentration on the conversion. Reaction conditions: anisyl alcohol at different concentrations (10-50 mM), propionic acid

(2 equiv.), $25 \mathrm{mg} / \mathrm{mL}$ Novozym 435, $50 \mathrm{mg} / \mathrm{mL}$ molecular sieves in 2-MeTHF, $800 \mathrm{rpm}, 30^{\circ} \mathrm{C}, 12 \mathrm{~h}$.

As shown in Figure 2 by increasing the substrate concentration a gradually decrease of conversion was observed from $97.8 \%$ (10 mM anisyl alcohol) to $70.2 \%$ (50 mM substrate). It was emphasized that the continuous lowering of the conversion could be determined by the inefficient removal of the water from the reaction mass due to the insufficient quantity of molecular sieves $(50 \mathrm{mg} / \mathrm{mL})$ in the reaction medium.

\section{Influence of the molecular sieves on the conversion}

Accordingly, further the influence of the molecular sieves load upon the efficacy of the enzymatic esterification was investigated at constant anisyl alcohol $(50 \mathrm{mM})$ and propionic acid $(100 \mathrm{mM})$ concentrations at $30{ }^{\circ} \mathrm{C}$ temperature, as presented in Figure 3. 


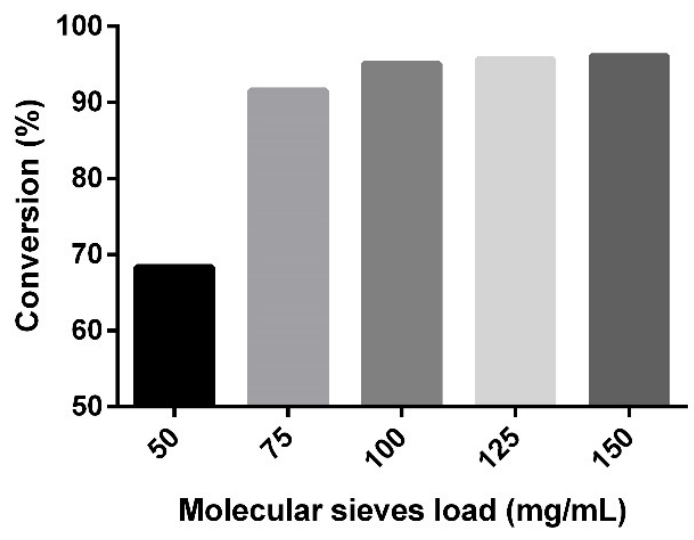

Figure 3. The influence of the molecular sieves load upon the conversion of anisyl alcohol into anisyl propionate. Reaction conditions: $50 \mathrm{mM}$ anisyl alcohol in 2-MeTHF,

2 equiv. of propionic acid, $25 \mathrm{mg} / \mathrm{mL}$ Novozym 435, $800 \mathrm{rpm}, 30{ }^{\circ} \mathrm{C}, 12 \mathrm{~h}$.

Increasing the molecular sieves load, the conversion of the esterification was considerably improved, from $68.4 \%(50 \mathrm{mg} / \mathrm{mL}$ molecular sieves) up to $95.1 \%$ in presence of $100 \mathrm{mg} / \mathrm{mL}$ of molecular sieves (Figure 3). Higher amounts (125 and $150 \mathrm{mg} / \mathrm{mL}$ ) of molecular sieves did not improve considerably the reaction conversion. At $150 \mathrm{mg} / \mathrm{mL}$ molecular sieves load the reaction conversion was enhanced only with $1 \%$, compared to reactions carried out in presence of $100 \mathrm{mg} / \mathrm{mL}$ drying agent. Therefore, further optimization experiments were performed in presence of $100 \mathrm{mg} / \mathrm{mL}$ molecular sieves.

\section{Temperature screening}

Temperature plays a major role in the kinetics of any reaction. In this context, the influence of temperature upon biocatalyst activity and stability was further studied in experiments which were setup under the previously determined optimum conditions. Samples from the reaction mixtures were taken periodically ( 2 hours intervals), analyzed and results were plotted as shown in Figure 4.

It was demonstrated that Novozym 435 is a stable and active biocatalyst even at $60{ }^{\circ} \mathrm{C}$. Analyzing the temperature dependence of the conversion profiles as depicted in Figure 4, it can be concluded that at $60{ }^{\circ} \mathrm{C}$ the previously determined maximal reaction conversion ( 96\%) was achieved after only 6 hours. Based on this study the optimum temperature was chosen to be $60{ }^{\circ} \mathrm{C}$, as it halves the time necessary for the almost complete substrate conversion into the desired product. 


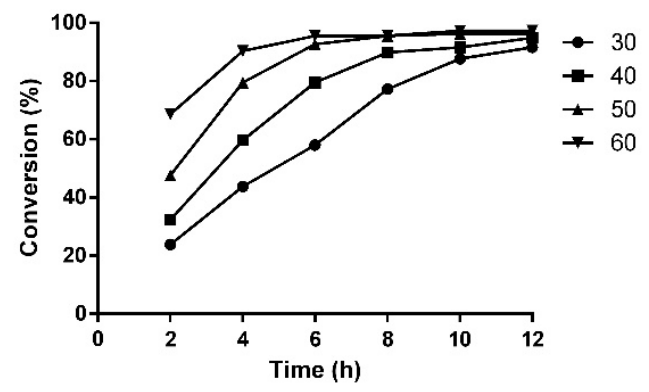

Figure 4. Temperature effect upon the efficacy of the enzymatic esterification of anisyl alcohol with propionic acid. Reaction conditions: $50 \mathrm{mM}$ anisyl alcohol,

2 equiv. propionic acid, $25 \mathrm{mg} / \mathrm{mL}$ Novozym 435, $100 \mathrm{mg} / \mathrm{mL}$ molecular sieves in 2-MeTHF, $800 \mathrm{rpm}$.

\section{Process scale-up in optimum conditions}

With all these results in hands, which jointly were associated with the optimal conditions for the analytical scale enzymatic synthesis of anisyl propionate, next the improvement of reaction productivity was studied. Maintaining the biocatalyst and molecular sieves load and the reactants molar ratio, the substrate concentration was further incrementally increased with 10 units in 60-100 mM substrate concentration domain. Since the performance of the developed reaction system was unaltered even at $100 \mathrm{mM}$ substrate concentration, further reactions were performed at much higher anisyl alcohol content $(200,300,500$ and $1000 \mathrm{mM})$ and the reaction mixtures were analyzed after 6 hours reaction time (Figure 5).

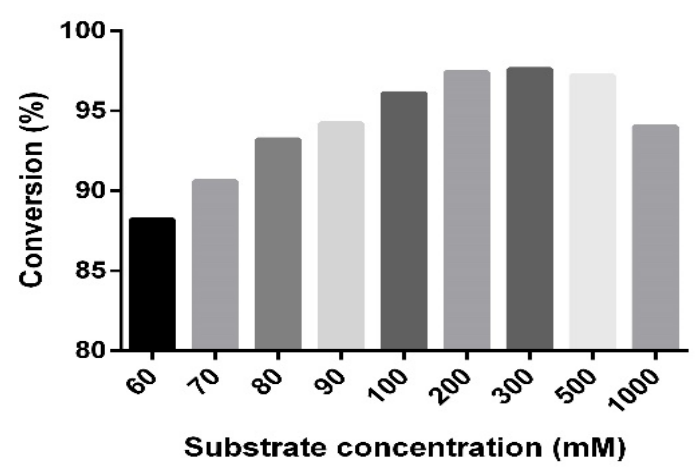

Figure 5. Process scale-up under optimum conditions. Reaction conditions: 60$1000 \mathrm{mM}$ anisyl alcohol, 2 equiv. propionic acid, $25 \mathrm{mg} / \mathrm{mL}$ Novozym 435, 100 $\mathrm{mg} / \mathrm{mL}$ molecular sieves in 2-MeTHF, $800 \mathrm{rpm}, 60^{\circ} \mathrm{C}, 6 \mathrm{~h}$. 
Ascending the substrate concentration in $10-100 \mathrm{mM}$ range, the conversion of the biocatalytic reaction continuously increased from 88 to $95 \%$, after 6 hours of reaction time. These results can be explained by the dependence of the reaction rate on the reagents concentration, but also demonstrated the absence of the substrate or product inhibition upon enzyme activity. Moreover, it was also concluded that the biocatalyst was used under its maximal capacity. These facts encouraged additional experiments with further increasing the substrate concentration, as illustrated in Figure 5. It is important to note that the conversion after 6 hours reaction time was similar ( 95\%) also for $1000 \mathrm{mM}$ substrate concentration, as compared with those performed at lower concentrations. This result determined us to work-up and isolate the formed ester. The purified ester was obtained with $92 \%$ yield and its structure was confirmed by NMR spectroscopy.

\section{CONCLUSIONS}

Anisyl propionate was successfully prepared by the enzymatic esterification mediated by Novozym 435 in a green solvent (2-MeTHF) employing molecular sieves as efficient water removal tool. After process optimization, anisyl propionate was obtained with $92 \%$ yield starting from anisyl alcohol in $1000 \mathrm{mM}$ concentration. Therefore, the newly developed reaction system can be considered a viable candidate for a potential industrial scale-up.

\section{EXPERIMENTAL SECTION}

\section{Materials}

Novozym 435 was purchased from Novozyme (Denmark). Molecular sieves ( $2 \mathrm{~mm}$ granule dimension, $5 \AA$ pore dimension) were purchased from Sigma-Aldrich (St. Louis, MO, USA). Anisyl alcohol, propionic acid, 2-Methyltetrahydrofuran (2-MeTHF), $n$-hexane, acetone, methyl tert-butyl ether (MTBE), dichloromethane, sodium bicarbonate and sodium sulphate were purchased from Merck (Germany). Anisyl propionate, used as standard, was previously synthesized in the Enzymology and Applied Biocatalysis Research Center, Cluj Napoca. All solvents and reagents were freshly distilled and dried by standard methods before use.

Reactions were incubated under shaking using a Vibramax 110 equipped with a temperature-control module (Heidolph). The enzymatic reactions were monitored using an Agilent HPLC 1206 Infinity series (Santa Clara, CA, USA), equipped with a UV-Vis detector, using a Phenomenex Gemini NX-C18 $(150 \times 4.5 \mathrm{~mm} ; 5 \mu \mathrm{m})$ chromatographic column. 


\section{Methods}

\section{Conversion determination}

The reaction conversions were determined using reversed phase liquid chromatography. The compounds were separated on a Gemini NX-C18 chromatographic column, with a mix of methanol: water 80:20 (v/v), as mobile phase at $0.5 \mathrm{~mL} \times \mathrm{min}^{-1}$ flow rate, monitoring the absorbance at $208 \mathrm{~nm}$. In order to rigorously determine the conversion of anisyl alcohol into anisyl propionate a relative response factor was determined $\left(R_{F}=0.9204\right)$ by injecting samples of known concentration of alcohol and ester in different molar ratios.

\section{Solvent screening}

$1.38 \mathrm{mg}$ anisyl alcohol and $1.48 \mathrm{mg}$ (2 equiv.) of propionic acid were mixed in $1 \mathrm{~mL}$ organic solvent. $25 \mathrm{mg}$ of Novozym 435 and $50 \mathrm{mg}$ of molecular sieves were added in the reaction medium. The reactions were shaken $(800 \mathrm{rpm})$ at $30^{\circ} \mathrm{C}$ for $12 \mathrm{~h}$. After $12 \mathrm{~h} 25 \mu \mathrm{L}$ samples were taken and evaporated. Samples were reconstituted with $1 \mathrm{~mL}$ mobile phase, filtered and injected in order to determine the conversion.

\section{Substrate concentration screening}

In $1 \mathrm{~mL} 2-$ MeTHF different quantities of anisyl alcohol (1.38, 2.76, $4.14,5.52$ and $6.9 \mathrm{mg}$ ), propionic acid (respecting the alcohol: acid molar ratio of 1:2), Novozym $435(25 \mathrm{mg})$ and molecular sieves $(50 \mathrm{mg})$ were added. Reactions were perfected and sampling was performed as described in the previous section.

\section{Influence of the molecular sieves load upon the conversion}

In $1 \mathrm{~mL}$ solution of anisyl alcohol $(50 \mathrm{mM})$ and propionic acid $(100 \mathrm{mM}$, 2 equiv.) in 2-MeTHF $25 \mathrm{mg}$ of Novozym 435 and different quantities of molecular sieves $(50,75,100,125$ and $150 \mathrm{mg})$ were added. Reactions were perfected and sampling was performed as described in the previous sections.

\section{Temperature screening}

In $1 \mathrm{~mL}$ solution of anisyl alcohol $(50 \mathrm{mM})$ and propionic acid $(100 \mathrm{mM}$, 2 equiv.) in 2-MeTHF, Novozyme 435 (25 mg) and $100 \mathrm{mg}$ of molecular sieves were added. The reactions were shaken $(800 \mathrm{rpm})$ at $30,40,50$ and $60{ }^{\circ} \mathrm{C}$ for 12 hours. Sampling was performed after 2, 4, 6, 8, 10 and 12 hours by taking $25 \mu \mathrm{L}$ samples and evaporating them. The samples were reconstituted with $1 \mathrm{~mL}$ mobile phase, filtered and analyzed by HPLC. 
ECO-FRIENDLY ENZYMATIC SYNTHESIS OF ANISYL PROPIONATE MEDIATED BY LIPASE B FROM CANDIDA ANTARCTICA

\section{Process scale-up in optimum conditions}

In $1 \mathrm{~mL}$ solution of anisyl alcohol $(60,70,80,90,100,200,300,500$ and $1000 \mathrm{mM}$ ) and propionic acid (2 equiv.) in 2-MeTHF, Novozym $435(25 \mathrm{mg})$ and $100 \mathrm{mg}$ of molecular sieves were added. The reactions were shaken (800 rpm) at $60{ }^{\circ} \mathrm{C}$ for $6 \mathrm{~h}$. Samples $(25 \mu \mathrm{L})$ were taken and evaporated. Samples were reconstituted with $1 \mathrm{~mL}$ mobile phase, filtered and analyzed by HPLC.

The reaction performed on $1000 \mathrm{mM}$ alcohol solution was worked up and the structure of purified product (anisyl propionate) was confirmed by NMR spectroscopy. For this, the reaction mixture was filtered in order to remove the enzyme and the molecular sieves. Next, 2-MeTHF was evaporated under reduced pressure, the reaction mass was redissolved in $5 \mathrm{~mL}$ dichloromethane and washed with sodium bicarbonate solution $(1 \mathrm{M} ; 2 \times 5 \mathrm{~mL})$ for isolating the unreacted propionic acid. The separated organic layer was extracted and dried over sodium sulphate. Further purification by column chromatography was performed using dichloromethane as eluent.

${ }^{1} \mathrm{H}-\mathrm{NMR}\left(400 \mathrm{MHz}, \mathrm{CDCl}_{3}\right): 1.17(3 \mathrm{H}, t), 2.38(2 \mathrm{H}, q), 3.83(3 \mathrm{H}, s)$, $5.07(2 \mathrm{H}, s), 6.91(2 \mathrm{H}, d), 7.32(2 \mathrm{H}, d) ;{ }^{13} \mathrm{C}-\mathrm{NMR}\left(100 \mathrm{MHz}, \mathrm{CDCl}_{3}\right)$ : 9.1, $27.6,55.3,66,113.9,128.2,130.1,159.6,174.4$.

\section{ACKNOWLEDGMENTS}

The present work has received financial support through the project: Entrepreneurship for innovation through doctoral and postdoctoral research, POCU/380/6/13/123886 co-financed by the European Social Fund, through the Operation Program for Human Capital 2014-2020.

\section{REFERENCES}

1. M.A. Longo; M.A. Sanroman; Food Technol. Biotechnol.; 2006; 44; 335-353

2. A.G. Almeida Sa; A.C. de Meneses; L.A. Lerin; P.H.H. de Araujo; C. Sayer; D. de Oliveira; Bioproc. Biosyst. Eng.; 2018; 41; 585-591

3. A.I. Dudu; M.A. Lăcătuș; L.C. Bencze; C. Paizs; M.I. Toșa; ACS Sustain. Chem. Eng.; 2021; 9; 5461-5469

4. M. Sarno; M. Iuliano; M. Polichetti; P. Ciambelli; Process Biochem.; 2017; 56; 98-108

5. C. Vasilescu; A. Todea; A. Nan; M. Circu; R. Turcu; I.C. Benea; F. Peter; Food Chem.; 2019; 296; 1-8 
6. A.C. de Meneses; A.G. Almeida Sa; L.A. Lerin; M.L. Corazza; P.H.H. de Araujo; C. Sayer; D. de Oliveira; Process Biochem.; 2019; 78; 50-57

7. Z. Gao; J. Chu; T. Jiang; T. Xu; B. Wu; B. He; Process Biochem.; 2018; 64; 152-159

8. S. Asmat; A.H. Anwer; Q. Husain; Int. J. Biol. Macromol.; 2019; 140; 484-495

9. O. Barbosa; C. Ortiz; R. Torres; R.F. Lafuente; J. Mol. Catal. B Enzym.; 2011; $71 ; 124-132$

10. J.L.R. Friedrich; F.P. Pena; C. Garcia-Galan; R. Fernandez-Lafuente; M.A.Z. Ayub; R.C. Rodrigues; J. Chem. Technol. Biotechnol; 2012; 88; 1089-1095

11. M.C.M. de Souza; K.P. dos Santos; R.M. Freire; A.C.H. Barreto; P.B.A. Fechine; L.R.B. Goncalves; Braz. J. Chem. Eng.; 2017; 34; 681-690

12. H.V. Ferreira; L.C. Rocha; R.P. Severino; A.L.M. Porto; Molecules; 2012; 17; 8955-8967

13. R.N. Patel; A. Banerjee; V. Nanduri; A. Goswami; F.T. Comezoglu; J. Am. Oil Chem. Soc.; 2000; 77; 1015-1019

14. V. Pace; P. Hoyos; L. Castoldi; P.D. de Maria; A.R. Alcantara; ChemSusChem; 2012; 5 ; 1369-1379

15. M.A. Lacatus; L.C. Bencze; M.I. Toșa; C. Paizs; F.D. Irimie; ACS Sustain. Chem. Eng.; 2018; 6; 11353-11359 